\title{
Attitudes of general practitioners and child psychiatrists to treatment methods
}

\author{
Theodore I.R. Mutale
}

\begin{abstract}
The introctuction of the now contract and budgotholding practices has given general practitioners more soy in the care given to their polients by secondary care units and other providers of health care. It is therefore important that the viows of GPs bo taken into account when service requirements are dotermined. This study compares the treatment choices of GPs with those of consultiant child poychiatitits in the management of chilchood peychological disorder. The doctors were also asked to inclicale treatiments they thought were harmfll or ineflective. To the best of my knowledge this is the first UK study to compare child poychiatists' and GPs' treatment priortiles.
\end{abstract}

\section{The study}

A random sample of 100 general practitioners was chosen from the medical directories of two East London Family Health Service Units using a random numbers table (Daniel, 1991). The two units cover Hackney, Newham, Tower Hamlets, Waltham Forest and Redbridge. The GPs were sent a questionnaire with a personally addressed covering letter in July and August 1992. Two weeks later GPs who had not responded were sent a reminder together with a second questionnaire. The questionnaire had the following items: age; sex; years in general practice; higher qualifications; paediatric training; psychiatric training; duties outside general practice; and a list of 14 treatments. GPs were asked to rank each treatment according to effectiveness and versatility, and to take into account their willingness to pay for the treatment if they had been made budget holders.

A random numbers table (Daniel, 1991) was used to select 50 consultant child psychiatrists from a medical directory containing names of consultants employed by NHS units in the United Kingdom. The child psychiatrists were also sent a questionnaire with a personally addressed covering letter. They were asked to rank 14 treatments according to effectiveness and versatility, and to indicate any treatment methods they considered dangerous or ineffective. Two weeks later child psychiatrists who had not responded were sent a reminder together with a second questionnaire.

The list of treatments sent to child psychiatrist and GPs was identical. Treatments could be ranked from 1 to 14 and there was no restriction on the number of treatments that could be given the same rank. The treatments listed were: individual counselling; individual analytic psychotherapy; family therapy; cognitive therapy; behaviour therapy; art therapy; drama therapy; music therapy; homeopathy; dietary changes; group therapy: therapeutic community; drugs; and electroconvulsive treatment (ECT).

$\chi^{2}$ and Fishers's exact test were used in the data analysis.

\section{Findings}

Out of 100 GPs, 65 returned fully completed questionnaires. They had the following characteristics: mean age 42.4 (s.d., 10.7); 38 (58\%) men; 37 (42\%) women; 49 (75\%) were vocationally trained; $41(63 \%)$ had done a paediatric hospital job; 25 (39\%) a psychiatric hospital job; 22 (34\%) had the MRCGP; 10 (15\%) the DCH; 15 (23\%) had other higher qualifications; and 15 (23\%) had a job outside general practice.

The characteristics of GPs who failed to respond were obtained from the medical directories. Of the 35 non respondents, 22 (63\%) were men; 13 (37\%) women; 10 (29\%) had the MRCGP; $4(11 \%)$ the DCH; and $15(23 \%)$ had a job outside general practice. The main reason given for non completion of questionnaires was pressure of work. Out of $\mathbf{5 0}$ consultant child psychiatrists, 41 returned completed questionnaires.

GPs' most popular choice for each of ranks 1 to 14 was: family therapy (rank 1), chosen by 36 out of 65 (55\%); counselling (20\%); behaviour therapy (14\%); analytic psychotherapy (9\%); group psychotherapy (20\%); group psychotherapy (8\%); therapeutic community (11\%); therapeutic community (11\%); art therapy (9\%); music therapy (11\%); homeopathy (5\%); 
drugs (5\%); homeopathy $(8 \%)$; and rank 14 , ECT (9\%).

Child psychiatrists' most popular choice for each of ranks 1 to 14 was: family therapy (rank 1), chosen by 27 out of 41 (66\%); counselling (37\%); cognitive therapy (22\%); group therapy (17\%); behaviour therapy (15\%); analytic psychotherapy (10\%); group therapy (10\%); group therapy (10\%); drugs (10\%); music therapy (5\%); drama therapy (7\%); drugs (10\%); drama therapy (5\%); and rank 14, ECT (10\%).

Both GPs and chid psychiatrists chose family therapy and individual counselling as their most popular first and second choices respectively. ECT was placed 14th by both groups of doctors. There were differences in positions given to the other treatments. Some treatments were the most popular at more than one position.

Treatments were also ranked according to the number of GPs who thought a treatment was ineffective or dangerous, or both. The rank order, starting with the most ineffective or dangerous treatment was: ECT, chosen by 26 out of 65 (40\%); homeopathy (35\%); drama therapy (30\%); music therapy (25\%); art therapy (23\%); dietary changes (22\%); analytic psychotherapy (17\%); therapeutic community (15\%); drugs (9\%); cognitive therapy (5\%); behaviour therapy (5\%); family therapy (2\%); group therapy (2\%); and individual counselling $(0 \%)$.

For child psychiatrists the rank order, starting with the most dangerous or ineffective treatment, was: ECT, chosen by 26 out of 41 (63\%); homeopathy (41\%); dietary changes (29\%); music therapy (24\%); drama therapy (22\%); art therapy (15\%); analytic psychotherapy (10\%); therapeutic community (7\%); drugs (5\%); cognitive therapy (2\%); group therapy (2\%): behaviour therapy (0\%); family therapy (0\%); and individual counselling ( $0 \%)$.

There were more child psychiatrists than GPs who thought homeopathy was dangerous or ineffective $(P<0.01)$. At least a quarter of GPs thought music therapy, drama therapy, ECT and homeopathy were ineffective or dangerous. At least a quarter of child psychiatrists thought dietary changes, ECT and homeopathy were ineffective or dangerous.

\section{Comment}

The most striking finding was that both child psychiatrists and GPs thought family therapy was the most effective and versatile treatment method of all treatments avallable to child mental health services. Graham et al (1992) found that both referrers and clients were satisfied with practice based family therapy which suggests that it is acceptable and effective in primary care settings.

That at least a quarter of GPs thought art therapy, drama therapy, music therapy, homeopathy and analytic psychotherapy ineffective or dangerous has implications for child mental health units in that fund-holding GPs may be unwilling to pay for treatment packages that include these therapies. It is interesting that homeopathy was seen as ineffective or dangerous by significantly more child psychiatrists than GPs. This suggests that child psychiatrists are less convinced by 'alternative' therapies, such as homeopathy, than GPs.

While family therapy and individual counselling are the treatments of cholce for GPs and child psychiatrists, the two groups disagree in their ranking of the other treatments. This may lead to conflict between child psychiatrists and GPs when resources are scarce and treatment priorities have to be set.

\section{References}

DANIEL. W.W. (1991) Statistical tables. In Blostatics: a foundation for analysis in the health sctences, 5th edition. Singapore: John Wiley. Pp 687.

Graham, H., Senior, R., LAzARUS, M., MaYer, R. \& ASEN, K. (1992) Family therapy in general practice: views of referrers and clients. Brttish Journal of General Practice, 42. 25-28.

Theodore I.R. Mutale, Senior Registrar, Department of Psychological Medicine, Hospital for Sick Children, Great Ormond Street, London WCI 